\title{
Seleção e associação de cultivares de milho com Beauveria bassiana para o controle de Sitophilus zeamais (Coleoptera: Curculionidae)
}

\author{
Selection and association of resistent varieties of corn with \\ Beauveria bassiana for control of \\ Sitophilus zeamais (Coleoptera: Curculionidae)
}

\author{
Michele Potrich $^{1 *}$; Luis Francisco Angeli Alves ${ }^{1,3}$; Natália Ramos Mertz ${ }^{2}$; \\ Andréia Kusumota Bonini²; Everton Ricardi Lozano da Silva²; \\ Luiz Paulo Calixto Marchese ${ }^{2}$
}

\begin{abstract}
Resumo
Este trabalho teve como objetivo associar estratégias de controle visando minimizar os danos provocados por Sitophilus zeamais em milho. Cultivares de milho resistentes e suscetíveis ao inseto foram submetidas aos testes com e sem chance de escolha. Posteriormente, as selecionadas foram associadas ao fungo Beauveria bassiana (isolados Unioeste 4 e Esalq 643), previa e posteriormente à infestação por S. zeamais. Verificou-se que a cultivar CD 3121 apresentou resistência, aumentando a duração do ciclo ovo-adulto, diminuindo o número de insetos emergidos e diminuindo a perda de peso dos grãos, e não-preferência para alimentação pelo inseto, ao contrário da cultivar CD 307. A associação mostrou-se positiva para o controle dos insetos, pois causou aumento na duração do ciclo ovo-adulto, diminuição no número de insetos emergidos, diminuição na porcentagem de grãos danificados e diminuição na perda de peso, tanto para a cultivar CD 3121 quanto para a cultivar CD 307, para ambos isolados. Contudo, a associação dos isolados com a cultivar CD 3121 foi mais efetiva para o controle de S. zeamais.

Palavras-chave: Variedades resistentes, fungo entomopatogênico. gorgulho do milho
\end{abstract}

\begin{abstract}
This work had as objective to associate control strategies to minimize the damage caused by Sitophilus zeamais in corn. Corn cultivars, resistant and susceptible to insect, were submitted to tests, with and without choice. Then, the selected cultivars were associated with the fungus Beauveria bassiana (Unioeste 4 and Esalq 643 isolates), before and after S. zeamais infestation. It was verified that the cultivar CD 3121 presented resistence, increasing the duration of the egg-adult cicle, decreasing the number of emerged insects and decreasing the weight loss of the grains, and showed non-preference to feeding by the insect, when compared to cultivar CD 307. The association caused an increase in the duration of the egg-adult cycle, decreasing of the number of emerged insects, decreasing percentage damaged grains and decreasing weight loss, for both cultivars CD 3121 and CD 307, and for both isolates. On the other hand, the isolates association with cultivars CD 3121 had a better control of $S$. zeamais.
\end{abstract}

Key words: Resistent varieties, entomopathogenic fungi, association, maize weevil

1 Universidade Tecnológica Federal do Paraná - Campus Dois Vizinhos (UTFPR-DV). E-mail: michelepotrich@utfpr.edu.br; profmichele@gmail.com

2 Universidade Estadual do Oeste do Paraná, Campus Cascavel, CCBS, Laboratório de Zoologia de Invertebrados. lfaalves@ unioeste.br, nataliaramosmertz@gmail.com, akbonini@yahoo.com.br, evertonloz@gmail.com, lupacama@gmail.com

3 Bolsista de Produtividade em Pesquisa pelo Conselho Nacional de Desenvolvimento Científico e Tecnológico (CNPq). Email: lfaalves@unioeste.br

* Autor para correspondência 


\section{Introdução}

O milho é uma das mais importantes culturas, sendo a área total plantada, no Brasil, de 12.490.800 ha, na safra 2005/06. O estado do Paraná se destacou nos últimos 15 anos, e nessa mesma safra chegou a 4.362.200 ha, o que corresponde a 35\% da área nacional cultivada com milho (BRASIL, 2005a, 2005b).

O milho, após o plantio é colhido e armazenado, porém, quando isso é feito sem os devidos cuidados, sofre perdas causadas pelas pragas de produtos armazenados (GALLO et al., 2002).

Dentre elas, os insetos têm maior importância no milho armazenado, sendo que as espécies Sitophilus oryzae e $S$. zeamais (Coleoptera: Curculionidae) são responsáveis pelos maiores danos e prejuízos na sua qualidade. Estes insetos são pequenos besouros, medindo cerca de $3 \mathrm{~mm}$, conhecidos como gorgulhodo-arroz e gorgulho-do-milho, respectivamente (LORINI, 1999; GALLO et al., 2002). Estes, além de romperem o grão e se alimentarem do endosperma, possibilitam a instalação de outros agentes de deterioração (SANTOS, 1993; LORINI, 1999).

$\mathrm{O}$ ataque desses insetos torna o milho impróprio para a industrialização, para o consumo humano e alimentação animal, devido à perda da qualidade nutritiva e presença de contaminações. Além disso, no produto final também ocorre a perda em peso, sendo os danos irreversíveis. Com a redução na qualidade, o milho passa a sofrer graves quedas na sua classificação comercial (CANEPPELE et al., 2003).

O controle desses insetos é baseado no uso de produtos químicos, como o expurgo com fosfina (fosfeto de alumínio ou fosfeto de magnésio). No entanto, há estudos que demonstram a persistência desses produtos nos alimentos e no ambiente, além de serem tóxicos aos aplicadores e selecionarem populações de insetos resistentes (GALLO et al., 2002).

A demanda mundial por alimentos cada vez mais saudáveis exige que a qualidade do grão colhido na lavoura seja mantida, e com o mínimo possível de perdas, além da racionalização quanto à utilização dos produtos químicos. Ressalta-se, dessa forma, a importância do manejo integrado de pragas (MIP).

Nas pesquisas, os inimigos naturais, em especial os fungos entomopatogênicos, têm destaque no controle de insetos-praga de grãos armazenados (HIDALGO; MOORE, LE PATOUREL, 1998; MOINO JÚNIOR; ALVES; 1998; PADÍN; DAL BELLO; FABRIZIO, 2002). Tais entomopatógenos são os organismos que apresentam maior potencial de uso no controle de Sitophilus spp., pois seu modo de ação é baseado, principalmente, no contato do inseto com os conídios, além de exigirem menor umidade no ambiente em relação aos nematóides (ALVES; LECUONA, 1998; AZEVEDO, 1998).

As plantas resistentes a insetos, no MIP, também são consideradas um método ideal de controle, pois possibilitam a manutenção da praga em níveis inferiores aos níveis de dano (LARA, 1991; GALLO et al., 2002).

Assim, tem-se procurado identificar e selecionar cultivares de milho resistentes, a fim de efetivar o controle de Sitophilus spp. (GUZZO et al., 2002; VENDRAMIM, 2002).

Vale ressaltar que cultivares resistentes não estão incluídas dentro do conceito de controle biológico, no entanto, podem favorecê-lo, e com base nisso, gerar um programa eficiente de MIP, pois segundo Lorini (2002), a integração de diferentes métodos de controle é uma prática essencial para se obter sucesso na supressão de insetos-praga de grãos armazenados.

A associação de métodos de controle para a supressão de insetos-praga vem sendo estudada e realizada com sucesso em outras culturas, como no arroz associado com B. bassiana para controle de $S$. oryzae (RICE; COGBURN, 1999) e no trigo associado também a $B$. bassiana para controle do pulgão Diuraphis noxia (HATTING et al., 2004). No entanto, não se tem relato da associação de cultivares de milho resistentes e fungos entomopatogênicos 
para o controle de $S$. zeamais, justificando com isso a integração destes métodos, visando um maior controle destes insetos sem causar maiores prejuízos ao ambiente.

Assim, o objetivo deste trabalho foi selecionar cultivares de milho resistentes ao ataque de $S$. zeamais e associá-las a isolados de Beauveria bassiana para avaliar a eficiência de controle.

\section{Material e Métodos}

Seleção das cultivares de milho

Foram utilizadas sementes de milho produzidas na safra 2004/2005, não submetidas a qualquer tratamento fitossanitário, fornecidas pela Cooperativa Central Agrícola (COODETEC), Cascavel, PR (Tabela 1).

Tabela 1. Relação de cultivares comerciais de milho utilizados no experimento e suas respectivas características físicas.

\begin{tabular}{llll}
\hline Cultivar $^{\mathbf{1}}$ & Tipo de híbrido & Tipo de grão & Cor do grão \\
\hline OC 705 & Duplo & Semi-duro & Alaranjado \\
CD 3121 & Simples & Semi-dentado & Amarelo \\
CD 304 & Triplo & Duro & Alaranjado \\
CD 306 & Triplo & Semi-duro & Alaranjado \\
CD 307 & Simples & Semi-dentado & Amarelo \\
CD 308 & Duplo & Semi-duro & Alaranjado \\
\hline
\end{tabular}

Fonte: Coodetec (2005)

${ }^{1} \mathrm{~A}$ citação dos materiais não implica em endosso por parte dos autores.

As sementes foram previamente inspecionadas, eliminando-se impurezas ou grãos imperfeitos que pudessem comprometer o experimento. Em seguida, foram armazenadas por 10 dias em freezer a $-10^{\circ} \mathrm{C}$, para eliminar os insetos nas diferentes fases de desenvolvimento eventualmente presentes na massa de grãos. Após este período, as sementes foram secas a $105^{\circ} \mathrm{C}$ por $24 \mathrm{~h}$, sendo a umidade final próxima de $13 \%$.

Adultos de Sitophilus zeamais, utilizados em todas as fases do experimento foram provenientes da criação do próprio laboratório, com idade entre 30 e 60 dias, não sexados, alimentados com grãos de arroz polido, para que não apresentassem condicionamento pré-imaginal por uma determinada cultivar de milho.

\section{Teste com chance de escolha}

Foram utilizadas bacias translúcidas com $35 \mathrm{~cm}$ de diâmetro $\times 15 \mathrm{~cm}$ de altura, com uma placa de isopor distanciada $5 \mathrm{~cm}$ do fundo, contendo aberturas circulares equidistantes, nas quais se encaixaram 6 recipientes plásticos com $2,5 \mathrm{~cm}$ de diâmetro $\times 2 \mathrm{~cm}$ de altura, dispostos radialmente, ficando todos com a abertura no mesmo nível que o suporte de isopor.

Em seguida, cada recipiente recebeu $20 \mathrm{~g}$ de sementes de cada um das cultivares de milho, sendo esta quantidade suficiente para preencher totalmente os recipientes. Na seqüência, foram liberados 120 insetos, adultos e não sexados, no centro da placa de isopor. Uma outra bacia igual foi colocada sobre esta de forma contrária e fechadas com fita adesiva.

As bacias foram deixadas em sala com fotoperíodo de 12 horas e temperatura média de $27 \pm 2^{\circ} \mathrm{C}$. Após 24 horas, foram realizadas contagens para verificar o número de insetos presentes em cada recipiente. Este procedimento foi repetido por 5 vezes, baseando-se na metodologia descrita por Guzzo et al. (2002).

O delineamento experimental foi inteiramente casualizado, sendo os dados analisados estatisticamente com a aplicação do teste $\mathrm{F}$ e as 
médias comparadas pelo teste de Tukey, ambos a 5\% de significância, utilizando-se o programa estatístico Sisvar ${ }^{\circledR}$ (FERREIRA, 2005). Os dados foram previamente transformados em arcseno $\sqrt{\times / 100}$, com auxílio do programa Microsoft Excel ${ }^{\circledR}$. As transformações de todos os dados, quando necessárias, foram feitas segundo o teste de F máximo de Hartley.

\section{Teste sem chance de escolha (confinamento)}

O teste foi realizado com as cultivares que apresentaram, respectivamente, a maior e a menor preferência no teste anterior. Para cada cultivar foram realizadas 10 repetições, cada qual com $20 \mathrm{~g}$ de milho e 20 insetos, sendo que cada uma foi disposta em um recipiente transparente de vidro com $6 \mathrm{~cm}$ de diâmetro $\times 6 \mathrm{~cm}$ de altura, fechado com um tecido fino. Foram ainda preparadas, para cada cultivar, 10 repetições com $20 \mathrm{~g}$ de material não contendo insetos, sendo consideradas testemunha.

Os recipientes foram mantidos durante sete dias em sala com fotoperíodo de 12 horas, temperatura média de $27 \pm 2^{\circ} \mathrm{C}$ e U.R. de $55 \%$ para que houvesse a infestação dos grãos. Posteriormente, os insetos foram retirados, e após 15 dias foram iniciadas as observações diárias, para acompanhar a emergência dos adultos. Os insetos emergidos foram retirados, contados e deixados em outro recipiente por 24 horas nas mesmas condições, e pesados em seguida, sendo este procedimento repetido por 70 dias, seguindo a metodologia de Guzzo et al. (2002) adaptada.

Foram avaliados, o número de insetos emergidos, o peso dos insetos adultos, a duração do ciclo ovoadulto, o número e o peso de grãos danificados. Para verificar os danos causados às sementes, como perfuração e perda de peso, os grãos danificados foram separados, contados e pesados. A perda de peso da matéria seca dos grãos foi determinada pela diferença entre o peso da matéria seca final da testemunha e o peso da matéria seca final dos tratamentos, segundo metodologia descrita por Toscano et al. (1999), enquanto a porcentagem foi feita por regra de três, considerando o peso final da testemunha como $100 \%$ e o peso final do tratamento como $\times$, seno o resultado extraído de $100 \%$.

A duração média do ciclo ovo-adulto foi calculada com base na média ponderada com auxílio do programa Microsoft Excel®. O delineamento experimental foi inteiramente casualizado e quando necessário, os dados foram transformados em arcseno $\sqrt{x / 100}, \sqrt{x}$ ou $\sqrt{x+1}$, sendo posteriormente submetidos à análise estatística, aplicando-se o teste $\mathrm{F}$ para analisar a variância e as médias foram comparadas pelo teste de Tukey, ambos a 5\% de significância, utilizando-se o programa estatístico Sisvar $^{\circledR}$ e Microsft Excel $^{\circledR}$.

\section{Associação das Cultivares Resistentes e Isolados de Beauveria bassiana}

Após a seleção das cultivares, foram realizados testes de estratégias de aplicação, sendo para isto utilizados isolados de B. bassiana selecionados para $S$. zeamais em trabalhos anteriores (POTRICH et al., 2006). Estes foram associados às cultivares resistente e a suscetível, previa e posteriormente à infestação por $S$. zeamais, seguindo metodologia descrita por Moino Júnior e Alves (1998).

\section{Associação pré-infestação}

Foram utilizados recipientes transparentes de vidro, com $6 \mathrm{~cm}$ de diâmetro $\times 6 \mathrm{~cm}$ de altura, fechados com um tecido fino. Os recipientes foram divididos em dois grupos, sendo que em 14 destes recipientes foram colocados $20 \mathrm{~g}$ da cultivar $\mathrm{CD}$ 3121 e nos outros 14 recipientes $20 \mathrm{~g}$ da cultivar CD 307 , selecionados no teste de confinamento e com umidade final próxima a $13 \%$.

Em seguida foi associado, em 7 recipientes de CD 3121 e 7 recipientes de CD 307, o isolado Unioeste 4 , na concentração de $0,27 \mathrm{~g} / 100 \mathrm{~g}$ de grãos (aproximadamente 2,0 × $10^{8}$ conídios/100g de grãos), sendo cada recipiente considerado uma 
repetição. O mesmo procedimento foi realizado com o isolado Esalq 643, na concentração de $0,2 \mathrm{~g} / 100 \mathrm{~g}$ (aproximadamente $2,0 \times 10^{8}$ conídios $/ 100 \mathrm{~g}$ de grãos), sendo que o fungo foi previamente misturado com amido de milho para maior dispersão.

Posteriormente, foram colocados 20 adultos não sexados de $S$. zeamais em cada recipiente, e estes foram armazenados em ambiente com temperatura média de $27 \pm 2^{\circ} \mathrm{C}$, fotofase de 12 horas e U.R. média de 55\%. Após sete dias da infestação, os insetos foram retirados e os recipientes voltaram para o mesmo ambiente. Avaliações, transformação de dados e análises estatísticas foram realizadas conforme descrito no teste sem chance de escolha ou de confinamento.

\section{Associação pós-infestação}

Este teste seguiu a metodologia descrita no teste de associação pré-infestação, para isto, insetos, recipientes, cultivares e isolados foram os mesmos descritos anteriormente e nos mesmos padrões de concentração e associação, assim como as condições de incubação. No entanto, para este teste, a aplicação do isolado nos recipientes foi realizada sete dias após a infestação, logo após a retirada dos insetos. Os métodos utilizados para as avaliações e transformações de dados foram os mesmos realizados para o experimento de testes sem chance de escolha.

Quandonecessário,os dados foram transformados em arcseno $\sqrt{x / 100}, \sqrt{x}$ ou $\sqrt{x+1}$, sendo posteriormente submetidos à análise estatística fatorial tipo $2 \times 2 \times 2$, sendo verificada a existência de interação entre os fatores cultivares, isolados e tipo de inoculção. Aplicou-se o teste F para se analisar a variância e as médias foram comparadas pelo teste de Tukey, ambos a 5\% de significância, utilizando-se o programa estatístico Sisvar $^{\circledR}$ e Microsft Excel ${ }^{\circledR}$.

Para os dois métodos de associação foi utilizada uma testemunha completa, sem infestação e sem associação, constando de apenas sete frascos de cada cultivar, contendo $20 \mathrm{~g}$ de grãos .

\section{Resultados e Discussão}

\section{Seleção das cultivares de milho}

\section{Teste com chance de escolha}

Observou-se que os insetos foram atraídos por todos as cultivares analisados, havendo diferenças significativas no percentual de insetos atraídos em cada um deles (Tabela 2).

Tabela 2. Porcentagem média de atratividade de $S$. zeamais para as diferentes cultivares comerciais de milho, em teste com chance de escolha, após $24 \mathrm{~h}$ de exposição.

\begin{tabular}{crl}
\hline Cultivares & Atratividade (\%)* & \\
\hline CD 304 & $19,3 \pm 4,50$ & AB \\
CD 306 & $4,0 \pm 1,10$ & B \\
CD 307 & $40,7 \pm 7,38$ & A \\
CD 308 & $6,3 \pm 1,41$ & B \\
CD 3121 & $8,2 \pm 3,00$ & B \\
OC 705 & $15,0 \pm 3,47$ & AB \\
\hline CV (\%) & 44,76 & \\
\hline
\end{tabular}

*Dados originais apresentados, para análise estatística os dados foram transformados em arcseno $\sqrt{\mathrm{x} / 100}$. Médias ( $\pm \mathrm{EP})$ seguidas pela mesma letra não diferem entre si, pelo teste de Tukey $(\mathrm{P}<0,05)$. 
A cultivar CD 307 foi o que apresentou, significativamente, maior atratividade a $S$. zeamais (40,7\%), enquanto os que apresentaram a menor atratividade foram as cultivares CD 306 (4\% de atratividade), CD 308 (6,3\%), e CD 3121 (8,2\%). Segundo Lara (1991), os menos atrativos nas condições analisadas apresentam uma resistência do tipo não-preferência ou antixenose para alimentação.

Em testes semelhantes, Toscano et al. (1999) verificaram a atratividade de $S$. zeamais para 10 cultivares de milho, sendo que nas cultivares mais atrativos observaram 24,7\% dos insetos, contra $3,1 \%$ nos menos atrativos, cujos valores foram inferiores aos obtidos neste experimento. Segundo os autores, as cultivares podem apresentar substâncias alimentares que interferem ou estimulam a alimentação dos insetos, assim, para estes, os materiais que atraem um menor número de insetos, possivelmente, apresentam um fator de repelência.

Nos experimentos realizados por Guzzo et al. (2002) a cultivar CD 3121 apresentou atratividade de $19 \%$ a $S$. zeamais, estando entre as três cultivares mais preferidos, enquanto neste trabalho apresentou $8,2 \%$ de atratividade, estando entre os três menos preferidos. Isto pode ter ocorrido pelo fato das cultivares aqui testados em confronto ao CD 3121, terem sido mais atrativos quando comparados as cultivares testados no outro trabalho, anulando assim a atratividade da cultivar CD 3121.

Verifica-se que para a maioria dos autores citados, a atratividade ou repelência de insetos por determinadas cultivares de milho, podem estar relacionadas com substâncias presentes ou liberadas pelos grãos, assim também destacado por Boiça Júnior, Lara e Guidi (1997) que relaciona ao odor e ao sabor dos grãos a atratividade de $S$. zeamais.

Contudo, Tipping et al. (1987), em experimentos realizados com extratos de diferentes cultivares de milho, observaram que substâncias aleloquímicas não estão relacionadas com a preferência à alimentação de $S$. zeamais, e Tipping et al. (1988) acrescentam que a composição do pericarpo, bem como a dureza do grão, são fatores determinantes, como também observado por Throne e Eubanks (2002), trabalhando com 'Tripsacorn'.

Apesar de grãos mais duros, mais escuros e mais pesados apresentarem menor preferência a S. zeamais, tais características, segundo Miranda et al. (1995), não são relevantes na explicação da preferência.

Considerando que as cultivares aqui analisadas que apresentaram não-preferência são do tipo semidura e alaranjada (CD 306 e CD 308) e semidentada e amarela (CD 3121), e a cultivar mais preferida é do tipo semidentada e amarelo (CD 307), verifica-se que a dureza e a cor do grão não interferiram na preferência alimentar do inseto, já que cultivares que apresentam o mesmo tipo de dureza e cor estão classificados como a mais e a menos preferida para alimentação de $S$. zeamais. Conclui-se que dureza e cor nem sempre podem ser associadas à resistência tipo não-preferência, contrariando Tipping et al. (1988).

Assim, pode-se observar que não há um consenso quanto ao que realmente interfere na preferência alimentar deste inseto em milho. Além disso, considerando que as cultivares altamente preferidas atraem uma grande proporção de insetos, restaram poucos para infestar as demais cultivares, de forma que estes podem ter escapado à infestação, e assim não tenham um fator de repelência em potencial (SANTOS; FOSTER, 1981a), e desta forma, foram selecionados as cultivares CD 307 e CD 3121.

Pode-se também considerar que o feromônio de agregação de $S$. zeamais possa ter agido, porém, segundo Wakefield et al. (2005), o feromônio apresenta resposta significativa em adultos com 1 a 2 dias de vida, sendo que esta atração diminui com a idade do inseto, de forma que provavelmente que este fator não tenha interferido neste trabalho. 
Teste sem chance de escolha (confinamento)

Verificou-se que na cultivar CD 3121 que apresentou não-preferência para a alimentação no primeiro teste, os insetos apresentaram maior duração no ciclo ovo-adulto (média de 52,5 dias). Já na cultivar CD 307, que demonstrou maior preferência para alimentação, os insetos apresentaram menor duração no ciclo, 47,5 dias (Tabela 3).

Tabela 3. Duração média do ciclo biológico, número e peso de adultos de $S$. zeamais emergidos das cultivares de milho, em teste sem chance de escolha.

\begin{tabular}{lccc}
\hline Cultivares & Duração do ciclo (dias) & Número de adultos emergidos* & Peso dos adultos (mg)* \\
\hline CD 307 & $47,5 \pm 0,72 \mathrm{~B}$ & $37,7 \pm 5,43 \mathrm{~A}$ & $2,4 \pm 0,02 \mathrm{~B}$ \\
CD 3121 & $52,5 \pm 0,91 \mathrm{~A}$ & $14,0 \pm 1,26 \mathrm{~B}$ & $2,5 \pm 0,05 \mathrm{~A}$ \\
\hline CV $(\%)$ & 2,33 & 26,66 & 1,66 \\
\hline
\end{tabular}

*Dados originais apresentados, para análise estatística os dados foram transformados em $\sqrt{\mathrm{x}}$.

Médias ( \pm EP) seguidas pela mesma letra na coluna não diferem entre si, pelo teste de Tukey $(\mathrm{P}<0,05)$.

Nos experimentos de confinamento com grãos debulhados, Ramalho, Rosseto e Nagai (1977) observaram duração média do ciclo variando entre 44,8 a 53,9 dias. Segundo estes, as cultivares nos quais a duração média foi menor foram considerados suscetíveis, pois favorecem o desenvolvimento de S. zeamais, tal como aqui observado na cultivar CD 307 que apresentou menor duração do ciclo (47,5 dias).

Bortoli (1987) obteve na cultivar considerado suscetível, ciclo médio de 44,4 dias e na cultivar resistente 48,4 dias, sendo estes valores menores dos aqui obtidos.

Boiça Júnior, Lara e Guidi (1997), apesar de terem obtido uma variação semelhante ao aqui verificado quanto ao ciclo biológico de $S$. zeamais (41,2 a 51,4 dias), não encontraram diferença significativa na duração do ciclo do inseto entre cultivares, corroborando os experimentos realizados por Toscano et al. (1999); Guzzo et al. (2002).

Nas cultivares avaliadas por Marsaro Júnior et al. (2005a), o ciclo biológico de $S$. zeamais apresentou variação de 38,87 a 46,62 dias, contudo, em outras cultivares Marsaro Júnior et al. (2005b) verificaram que a variação do ciclo biológico de $S$. zeamais foi de 51,5 a 58,4 dias.
A média do ciclo ovo-adulto na cultivar CD 3121 observado por Guzzo et al. (2002) foi de 49,85 dias, porém, Marsaro Júnior et al. (2005b) observou nesta mesma cultivar média de 55,6 dias e no presente trabalho a média foi de 52,5 dias, intermediária em relação às demais. Essas variações podem ser explicadas por diferenças nas condições em que o experimento foi mantido, sendo a temperatura um fator que pode acelerar ou retardar o desenvolvimento dos insetos, como observado por Pacheco e Paula (1995), em que o ciclo ovo-adulto de $S$. zeamais em milho, a $28^{\circ} \mathrm{C}$ e $60 \%$ U.R., mesmas condições do presente trabalho, teve média de 34 dias.

O número de insetos emergidos também é um fator a se considerar, pois segundo Guzzo et al. (2002), um dos mais importantes indicadores de antibiose é a morte larval, que pode ser expressa pelo baixo número de insetos emergidos. Estes observaram média de 12 a 15 insetos para as cultivares resistentes e 49 para os suscetíveis, sendo estes dados semelhantes ao do presente trabalho, com 14 insetos emergidos na cultivar resistente (CD 3121) e 37,7 insetos emergidos no suscetível (CD 307) (Tabela 3$)$.

Segundo Ramalho, Rosseto e Nagai (1977), existe uma relação entre duração do ciclo e número de adultos emergidos, determinando que quanto 
mais suscetível é o milho maior é o número de insetos emergidos e menor é o tempo que demoram a emergir, como ocorrido para a cultivar CD 307.

Santos e Foster (1981b) observaram que a maioria das cultivares que se mostraram como mais resistentes para a emergência e postura nos testes de confinamento, também foram os menos preferidos no teste de livre escolha. Ressalta-se assim, que a "não-preferência" e "antibiose" são mecanismos de resistência do grão de milho ao gorgulho, e que os dois testes se completam neste quesito, pois os mais suscetíveis também se apresentaram no presente trabalho como os mais preferidos.

Verificou-se diferença estatística em relação ao peso dos adultos emergidos, sendo $2,5 \mathrm{mg}$ para os insetos emergidos da cultivar CD 3121 e 2,4mg para os emergidos da cultivar CD 307 (Tabela 3). Na cultivar CD 3121 pode ter ocorrido não preferência (antixenose) para oviposição, no entanto, a qualidade nutricional pode ter interferido no desenvolvimento das fases imaturas, fazendo com que as mesmas apresentassem um ganho de peso.

Ainda que diferenças no peso dos adultos emergidos também tenham sido observadas por Toscano et al. (1999) (variação de 2,15 a 2,79 $\mathrm{mg}$ ), muitos autores não observaram variações significativas (VOWOTOR; BOSQUE-PÉREZ; AYERTEY, 1995; GUZZO et al., 2002; MARSARO JÚNIOR et al., 2005a, 2005b).

Verificou-se que houve diferença significativa quanto à perda total do peso dos grãos, sendo que para a cultivar CD 307 ocorreu 0,9g de perda de peso, enquanto para a cultivar CD 3121 a perda foi de $0,3 \mathrm{~g}$. A porcentagem de perda de peso total dos grãos também diferiu entre as cultivares, sendo para a cultivar CD 307 perda de $4,5 \%$ e para CD 3121 perda de $1,7 \%$. No entanto, para ambas cultivares não ocorreu diferença significativa quanto à porcentagem de grãos danificados (Tabela 4).

Tabela 4. Porcentagem média de grãos danificados, porcentagem média de perda total de peso dos grãos de milho e perda média total (g), causados por S. zeamais em teste sem chance de escolha.

\begin{tabular}{lccc}
\hline Cultivares & Grãos danificados (\%)* & ${\text { Perda total }(\mathbf{g})^{\mathbf{1 * *}}}^{*}$ & Perda total (\%) $^{\mathbf{1 *}}$ \\
\hline CD 307 & $44,8 \pm 4,59 \mathrm{~A}$ & $0,9 \pm 0,12 \mathrm{~A}$ & $4,5 \pm 0,61 \mathrm{~A}$ \\
$\mathrm{CD} 3121$ & $40,3 \pm 1,86^{\mathrm{A}}$ & $0,3 \pm 0,09 \mathrm{~B}$ & $1,7 \pm 0,44 \mathrm{~B}$ \\
\hline CV $(\%)$ & 17,82 & 11,38 & 36,88 \\
\hline
\end{tabular}

${ }^{1}$ Valores comparados às respectivas testemunhas.

*Dados originais apresentados, para análise estatística os dados foram transformados em $\operatorname{arcseno} \sqrt{\mathrm{x} / 100}$.

**Dados originais apresentados, para análise estatística os dados foram transformados em $\sqrt{x+1}$

Médias ( \pm EP) seguidas pela mesma letra na coluna não diferem entre si, pelo teste de Tukey $(\mathrm{P}<0,05)$.

Quanto à porcentagem de grãos danificados, as cultivares não diferiram entre si, relacionando este fator ao "teste de prova" de S. zeamais, deduzindo, desta forma, que estas duas cultivares utilizadas não apresentam ação repelente ou supressora sobre estes insetos. No entanto, pela diferença na perda de peso, verifica-se que a cultivar CD 3121 tem ação deterrente sobre o inseto, impedindo que este continue a se alimentar ou a ovipositar, diminuindo, com isso, a perda de peso dos grãos.
Conforme Matioli (1981), a perda de peso dos grãos atacados é um fator muito importante, pois além do aspecto econômico, também indica um fator de resistência.

Toscano et al. (1999) observaram que a perda média de peso dos grãos infestados com S. zeamais variou de uma cultivar para outra, com variação de $0,04 \mathrm{~g}$ a $0,70 \mathrm{~g}$. 
Ao contrário dos dados aqui obtidos, Guzzo et al. (2002) verificaram que a cultivar CD 3121 foi um dos mais atrativos e o mais suscetível ao ataque de $S$. zeamais, pois apresentou maior número de insetos emergidos, maior porcentagem e maior perda total de peso de grãos danificados.

A cultivar CD 3121, segundo Marsaro Júnior et al. (2005b) apresentou a menor perda de peso, tal como aqui observado. Também observaram um dos índices mais elevados de unidades inibidoras de amilase (UIA), que retardam o desenvolvimento das larvas, provocando menor alimentação e conseqüente, menores perdas nos grãos, aumentando a resistência desses, sendo classificado por esses autores como resistente.

A cultivar CD 3121 pode ser considerada resistente ao ataque de $S$. zeamais, pois apresentou maior duração do ciclo, menor número de insetos emergidos, menor porcentagem de perda e menor perda total de peso de grãos, além de estar entre as cultivares menos atrativas. Sua resistência, segundo Lara (1991); Gallo et al. (2002), pode ser classificada como não-preferência para postura.

\section{Associação das Cultivares Resistentes e Isolados de Beauveria Bassiana}

Verificou-se que a duração do ciclo de $S$. zeamais apresentou diferença significativa entre as cultivares CD 3121 e CD 307, quando tratados com o isolado Esalq 643, tanto pré (média de 66,7 dias na cultivar CD3121 e na cultivar CD 307 média de 50,5 dias) como pós-infestação (61,8 dias na cultivar CD 3121 e 50,1 dias na cultivar CD 307).

Por outro lado, com o isolado Unioeste 4 também ocorreram diferenças, mas apenas para o tratamento pós-infestação, sendo que na cultivar CD 3121 a média foi de 62,2 dias e na cultivar CD 307 de 50,2 dias. Nos demais tratamentos não houve qualquer diferença estatística (Tabela 5).

Tabela 5. Duração média do ciclo biológico de S. zeamais emergido nas cultivares CD 3121 e CD 307, tratados pré e pós-infestação dos insetos, com conídios de B. bassiana.

\begin{tabular}{lccccc}
\hline & \multicolumn{2}{c}{ CD 3121 } & & \multicolumn{2}{c}{ CD 307 } \\
\cline { 2 - 3 } \cline { 5 - 6 } & Pré-infestação & Pós-infestação $_{n n n n}$ & & Pré-infestação & Pós-infestação \\
\hline Unioeste 4 & $55,3 \pm 3,77 \mathrm{Ba}$ & $62,2 \pm 1,58 \mathrm{Aa}^{\text {n.s. }}$ & & $50,5 \pm 0,75 \mathrm{Aa}$ & $50,2 \pm 0,35 \mathrm{Ab}^{\text {n.s. }}$ \\
Esalq 643 & $66,7 \pm 4,18 \mathrm{Aa}$ & $61,8 \pm 0,50 \mathrm{Aa}^{\text {n.s. }}$ & & $50,5 \pm 1,56 \mathrm{Ab}$ & $50,1 \pm 1,42 \mathrm{Ab}^{\text {n.s. }}$ \\
\hline CV $(\%)=3,89$ & & & & \\
\hline
\end{tabular}

Médias originais apresentados, para análise estatística os dados foram transformados em $\sqrt{x}$.

Médias ( \pm EP) seguidas pela mesma letra maiúscula na coluna para cada cultivar, e pela mesma letra minúscula dentro do modo de infestação na linha, não diferem entre si, pelo teste de Tukey $(\mathrm{P}<0,05)$.

Médias ( \pm EP) seguidas não diferem entre si, pelo teste de Tukey $(\mathrm{P}<0,05)$.

n.s. Dentro da mesma cultivar, na linha, não diferem entre si, pelo teste de Tukey $(\mathrm{P}<0,05)$.

Esta diferença também foi verificada no teste de confinamento, contudo as médias foram inferiores às apresentadas neste experimento (52,5 dias para a cultivar CD 3121 e 47,5 dias para a cultivar CD 307). No entanto, verifica-se que a diferença entre as cultivares continua com a mesma tendência, como no experimento de confinamento.

Moino Júnior e Alves (1998) verificaram redução no ciclo ovo-adulto de $S$. zeamais quando os isolados foram aplicados pré-infestação (41 dias para o isolado Esalq 643 e 39,6 dias para o isolado Esalq 604), e atribuíram este fato a uma possível seleção, sendo que os adultos que sobreviveram eram mais vigorosos e deram origem a indivíduos também mais vigorosos, conseqüentemente, tendo menor ciclo.

Contudo, Batta (2004) verificou um aumento no ciclo de desenvolvimento de $S$. oryzae quando 
a infestação ocorreu em grãos de trigo tratados previamente com a associação de formulações de M. anisopliae em carvão vegetal e em cinzas.

Os insetos apresentaram ciclo médio de 55,3 dias quando o isolado Unioeste 4 foi associado préinfestação a cultivar CD 3121 e ciclo médio de 66,7 dias quando o isolado Esalq 643 foi associado a essa mesma cultivar.

Em relação ao número de insetos emergidos não houve diferença significativa na integração entre as cultivares, isolados e estratégias de aplicação (Tabela 6).

Tabela 6. Número de adultos de S. zeamais emergidos nas cultivares CD 3121 e CD 307 tratados pré e pós-infestação dos insetos, com conídios de B. bassiana.

\begin{tabular}{lcclcc}
\hline & \multicolumn{2}{c}{ CD 3121 } & & \multicolumn{2}{c}{ CD 307 } \\
\cline { 2 - 3 } \cline { 5 - 6 } & Pré-infestação & Pós-infestação & & Pré-infestação & Pós-infestação \\
\hline Unioeste 4 & $3,3 \pm 1,66 \mathrm{Aa}$ & $7,7 \pm 3,63 \mathrm{Aa}^{\text {n.s. }}$ & & $3,6 \pm 1,04 \mathrm{Aa}$ & $3,4 \pm 1,00 \mathrm{Aa}^{\text {n.s. }}$ \\
Esalq 643 & $1,6 \pm 0,57 \mathrm{Aa}$ & $5,0 \pm 1,38 \mathrm{Aa}^{\text {n.s. }}$ & & $2,6 \pm 1,31 \mathrm{Aa}$ & $3,3 \pm 1,46 \mathrm{Aa}^{\text {n.s. }}$ \\
\hline CV $(\%)=43,04$ & & & & \\
\hline
\end{tabular}

Dados originais apresentados, para análise estatística os dados foram transformados em $\sqrt{x+1}$.

Médias ( \pm EP) seguidas pela mesma letra maiúscula na coluna, para cada cultivar, e pela mesma letra minúscula na linha dentro do modo de infestação, não diferem entre si, pelo teste de Tukey $(\mathrm{P}<0,05)$.

n.s. Dentro da mesma cultivar, na linha, não diferem entre si, pelo teste de Tukey $(\mathrm{P}<0,05)$.

Por outro lado, Moino Júnior e Alves (1998) observaram diferenças no número de insetos emergidos em arroz nos tratamentos pré-infestação e pós-infestação, sendo que o isolado Esalq 643, testado por estes autores, apresentou média de 3,93 insetos quando aplicado previamente, e 8,07 quando aplicado posteriormente.

Adultos apresentaram peso médio maior $(2,8 \mathrm{mg})$ na cultivar CD 3121 tratado com Unioeste 4 préinfestação (Tabela 7), tal como observado no teste de confinamento. Isto confirma a hipótese de Moino Júnior e Alves (1998) sobre a seleção de insetos mais vigorosos ou ainda, a maior disponibilidade de nutrientes essenciais para o inseto nesta cultivar.

Assim a disponibilidade de nutrientes no alimento consumido na fase larval afeta a taxa de crescimento, o tempo de desenvolvimento, peso do corpo, sobrevivência, fecundidade, longevidade, movimentação e capacidade de competição dos adultos (PARRA, 1991).

Tabela 7. Peso médio de S. zeamais emergidos nas cultivares CD 3121 e CD 307 tratados pré e pós-infestação dos insetos, com conídios de B. bassiana.

\begin{tabular}{|c|c|c|c|c|}
\hline & \multicolumn{2}{|c|}{ CD 3121} & \multicolumn{2}{|c|}{ CD 307} \\
\hline & Pré-infestação & Pós-infestação & Pré-infestação & Pós-infestação \\
\hline Unioeste 4 & $2,8 \pm 0,11 \mathrm{Aa}$ & $2,6 \pm 0,07 \mathrm{Aa}^{\mathrm{n} . \mathrm{s} .}$ & $2,4 \pm 0,05 \mathrm{Ab}$ & $2,4 \pm 0,10 \mathrm{Aa}^{\mathrm{n} . \mathrm{s} .}$ \\
\hline Esalq 643 & $2,4 \pm 0,04 \mathrm{Ba}$ & $2,7 \pm 0,06 \mathrm{Aa}^{*}$ & $2,4 \pm 0,23 \mathrm{Aa}$ & $2,5 \pm 0,09 \mathrm{Aa}^{\text {n.s. }}$ \\
\hline
\end{tabular}

Dados originais apresentados, para análise estatística os dados foram transformados em $\sqrt{\mathrm{x}}$.

Médias ( \pm EP) seguidas pela mesma letra maiúscula na coluna, para cada cultivar, e pela mesma letra minúscula na linha, dentro do modo de infestação, não diferem entre si, pelo teste de Tukey $(\mathrm{P}<0,05)$.

n.s. Dentro da mesma cultivar, na linha, não diferem entre si, pelo teste de Tukey $(\mathrm{P}<0,05)$. 
Houve redução no peso dos insetos apenas quando o isolado Esalq 643 foi associado a cultivar CD 3121 no tratamento pré-infestação.

Analisando-se a porcentagem média de grãos de milho danificados, observou-se que não houve diferença significativa quanto aos isolados utilizados e as estratégias de aplicação adotadas. Porém, houve diferença significativa quanto a cultivar avaliada, sendo que a cultivar CD 3121 apresentou a menor porcentagem de grãos de milho danificados nos dois modos de associação. Para a associação pósinfestação a diferença ocorreu apenas em relação ao isolado Esalq 643 (Tabela 8).

Tabela 8. Porcentagem média de grãos de milho danificados por $S$ zeamais nas cultivares CD 3121 e CD 307 tratados pré e pós-infestação dos insetos, com conídios de B. bassiana.

\begin{tabular}{lcclcc}
\hline & \multicolumn{2}{c}{ CD 3121 } & & \multicolumn{2}{c}{ CD 307 } \\
\cline { 2 - 3 } \cline { 5 - 6 } & Pré-infestação & \multicolumn{1}{c}{ Pós-infestação } & & Pré-infestação & Pós-infestação \\
\hline Unioeste 4 & $12,3 \pm 1,11 \mathrm{Ab}$ & $16,2 \pm 1,57 \mathrm{Aa}^{\text {n.s. }}$ & & $24,9 \pm 1,93 \mathrm{Aa}$ & $23,4 \pm 3,18 \mathrm{Aa}^{\text {n.s. }}$ \\
Esalq 643 & $7,6 \pm 0,90 \mathrm{Ab}$ & $12,7 \pm 1,55 \mathrm{Ab}^{\text {n.s. }}$ & & $29,1 \pm 5,18 \mathrm{Aa}$ & $25,1 \pm 3,23 \mathrm{Aa}^{\text {n.s. }}$ \\
\hline $\mathrm{CV}(\%)=19,26$ & & & & \\
\hline
\end{tabular}

Dados originais apresentados, para análise estatística os dados foram transformados em arcseno $\sqrt{\mathrm{x} / 100}$.

Médias ( \pm EP) seguidas pela mesma letra maiúscula na coluna, para cada cultivar, e pela mesma letra minúscula na linha dentro do mesmo modo de infestação, não diferem entre si, pelo teste de Tukey $(\mathrm{P}<0,05)$.

n.s. Dentro da mesma cultivar, na linha, não diferem entre si, pelo teste de Tukey $(\mathrm{P}<0,05)$.

A diferença aqui apresentada pode estar relacionada com a provável repelência do fungo, que pode ter diminuído muitos testes de prova pelos insetos, danificando uma menor porcentagem de grãos. Além disso, associaram-se dois fatores, a cultivar considerado resistente e menos preferido para alimentação e o fungo.

Da mesma forma, Batta (2004) verificou redução nos danos provocados por S. oryzae em grãos de trigo, quando estes foram tratados previamente com a associação de formulações de $M$. anisopliae em carvão vegetal e em cinzas.

A perda de peso em gramas e a porcentagem média de perda de peso dos grãos de milho não apresentaram diferenças significativas entre os isolados testados e estratégias utilizadas. No entanto, entre a cultivar CD 3121 e CD 307, inoculados com o isolado Unioeste 4 pós-infestação, verificou-se diferença estatística quanto às perdas em gramas (Tabela 9 e 10).

Tabela 9. Perda de peso ${ }^{1}$ dos grãos de milho provocada por S. zeamais nas cultivares CD 3121 e CD 307 tratados pré e pós-infestação dos insetos, com conídios de B. bassiana.

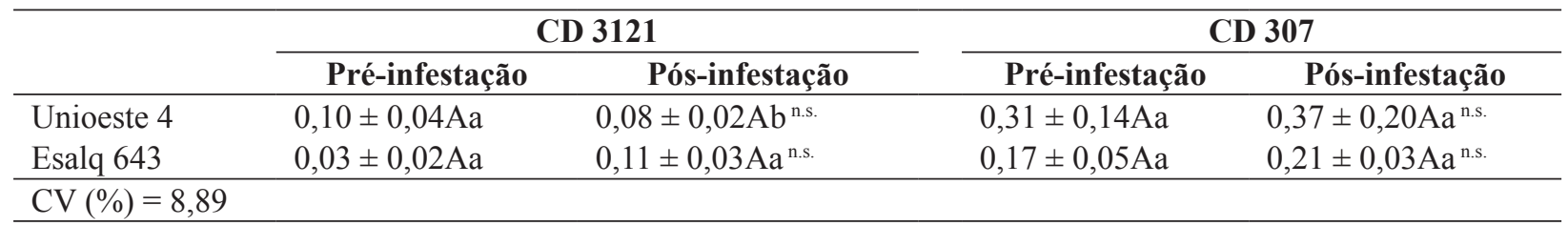

${ }^{1}$ Valores comparados às respectivas testemunhas.

Dados originais apresentados, para análise estatística os dados foram transformados em $\sqrt{x+1}$.

Médias ( \pm EP) seguidas pela mesma letra maiúscula na coluna, para cada cultivar, pela mesma letra minúscula na linha, dentro do modo de infestação, não diferem entre si, pelo teste de Tukey $(\mathrm{P}<0,05)$.

n.s. Dentro da mesma cultivar, na linha, não diferem entre si, pelo teste de Tukey $(\mathrm{P}<0,05)$. 
Tabela 10. Porcentagem média de perda de peso ${ }^{1}$ dos grãos de milho provocada por S. zeamais nas cultivares CD 3121 e CD 307 tratados pré e pós-infestação dos insetos, com conídios de B. bassiana.

\begin{tabular}{lcclcc}
\hline & \multicolumn{2}{c}{ CD 3121 } & & \multicolumn{2}{c}{ CD 307 } \\
\cline { 2 - 3 } \cline { 5 - 6 } & Pré-infestação & Pós-infestação & & Pré-infestação & Pós-infestação \\
\hline Unioeste 4 & $0,51 \pm 0,17 \mathrm{Aa}$ & $0,39 \pm 0,10 \mathrm{Aa}^{\text {n.s. }}$ & & $1,56 \pm 0,67 \mathrm{Aa}$ & $1,82 \pm 1,00 \mathrm{Aa}^{\text {n.s. }}$ \\
Esalq 643 & $0,13 \pm 0,08 \mathrm{Aa}$ & $0,55 \pm 0,17 \mathrm{Aa}^{\text {n.s. }}$ & & $0,86 \pm 0,27 \mathrm{Aa}$ & $0,96 \pm 0,14 \mathrm{Aa}^{\text {n.s. }}$ \\
\hline CV $(\%)=69,42$ & & & & \\
\hline
\end{tabular}

${ }^{1}$ Valores comparados às respectivas testemunhas.

Dados originais apresentados, para análise estatística os dados foram transformados em arcseno $\sqrt{\mathrm{x} / 100}$.

Médias ( \pm EP) seguidas pela mesma letra maiúscula na coluna, para cada cultivar, e pela mesma letra minúscula na linha, dentro do modo de infestação, não diferem entre si, pelo teste de Tukey $(\mathrm{P}<0,05)$.

n.s. Dentro da mesma cultivar, na linha, não diferem entre si, pelo teste de Tukey $(\mathrm{P}<0,05)$.

A cultivar CD 3121 apresentou 0,08g de perda quando comparado à testemunha (Tabela 9) e apesar desta diferença não ter sido verificada em relação à porcentagem de grãos danificados, também foi observada anteriormente no teste de confinamento, visto que esta cultivar é tido como resistente a $S$. zeamais.

Ao contrário do observado no presente trabalho, Padín, Dal Bello e Fabrizio (2002) observaram redução significativa na perda de peso provocada por $S$. oryzae em grãos de trigo tratados e não tratados com B. bassiana.

Observou-se que com a integração dos métodos de controle houve diminuição nos danos provocados pelo inseto, de forma que na cultivar CD 3121, tratado com o fungo, além de se mostrar mais resistente também apresentou diferença significativa quanto à porcentagem de grãos danificados, em relação a cultivar CD 307.

Verificou-se com estes experimentos que a associação dos métodos indica um potencial de utilização, recomendando-se a realização de testes com maiores concentrações de fungo para confirmar a eficiência dos tratamentos e também a realização em maior escala.

\section{Conclusões}

As cultivares de milho diferem entre si quanto à preferência alimentar e resistência a $S$. zeamais, sendo a cultivar CD 3121 considerada resistente e a cultivar CD 307 considerada suscetível em relação aos materiais testados.

A associação entre os isolados de $B$. bassiana (Unioeste 4 e Esalq 643) e a cultivar CD 3121 indica uma interação que pode ser usada no controle de $S$. zeamais.

\section{Referências}

ALVES, S. B.; LECUONA, R. E. Epizootiologia aplicada ao controle microbiano de insetos. In: ALVES, S. B. (Ed.) Controle microbiano de insetos. 2. ed. Piracicaba: FEALQ, 1998. p. 97-169. cap. 5.

AZEVEDO, J. L. Controle microbiano de insetos praga e seu melhoramento genético. In: MELO, I. S.; AZEVEDO, J. L. Controle biológico. v. 1. Jaguariúna: Embrapa, Ministério da Agricultura, Pecuária e Abastecimento, 1998. p. 69-96. cap. 2.

BATTA, Y. A. Control of rice weevil (Sitophilus oryzae L., Coleoptera: Curculionidae) with various formulations of Metarhizium anisopliae. Crop Protection, São Paulo, v. 23, n. 2, p. 103-108, 2004.

BOIÇA JÚNIOR, A. L.; LARA, F. M.; GUIDI, F. P. Resistência de genótipos de milho ao ataque de Sitophilus zeamais Mots. (Coleoptera: Curculionidae). An. Soc. Entomol., Piracicaba, v. 26, n. 3, p. 481- 485,1997. 
BORTOLI, S. A. Avaliação preliminar sobre o comportamento de alguns genótipos de milho em relação ao ataque de Sitophilus zeamais Mots., 1855 (Coleoptera: Curculionidae). Ciência Agronômica, Jaboticabal, v. 2, n. 1, p. 5-6, 1987.

BRASIL. Ministério da Agricultura, Pecuária e Abastecimento. Companhia Nacional de Abastecimento -CONAB. Levantamento de área plantada. Disponível em: < http:/www.conab.gov.br $>$. Acesso em: 30 dez. $2005 a$.

BRASIL. Ministério da Agricultura, Pecuária e Abastecimento. Empresa Brasileira de Pesquisa Agropecuária - EMBRAPA. Sete Lagoas: Embrapa Milho e Sorgo. Disponível em: <http://www.cnpms. embrapa.br>. Acesso: $27 \mathrm{dez}$. $2005 \mathrm{~b}$.

CANEPPELE, M. A. B.; CANEPPELE, C.; LÁZZARI, F. A.; LÁZZARI, S. M. N. Correlation between the infestation level of Sitophilus zeamais motschulsky, 1855 (Coleoptera, Curculionidae) and quality factors of stored corn, Zea mays L. (Poaceae). Revista Brasileira de Entomologia, São Paulo, v. 47, n. 4, p. 625-630, 2003.

COOPERATIVA CENTRAL DE PESQUISA AGRÍCOLA - COODETEC. Híbridos de milho. Cascavel. 2005. (Comunicado Técnico, on-line). Disponível em: < www.coodetec.com.br $>$ Acesso em: 10 jan. 2006.

FERREIRA, D. F. Sistema sisvar para análises estatísticas. Disponível em: <http://www.dex.ufla.br/ danielff/dff02.htm. . . Acesso: 23 dez. 2005.

GALLO, D.; NAKANO, O.; SILVEIRA NETO, S.; CARVALHO, R. P. L.; BAPTISTA, G. C.; BERTI FILHO, E.; PARRA, J. R. P.; ZUCCHI, R. A.; ALVES, S. B.; VENDRAMIM, J. D.; MARCHINI, L. C.; LOPES, J .R. S.; OMOTO, C. Entomologia agrícola. Piracicaba: FEALQ, 2002, 920 p. v. 10.

GUZZO, E. C.; ALVES, L. F. A.; ZANIN, A.; VENDRAMIN, J. D. Identificação de materiais de milho resistentes ao ataque de gorgulho Sitophilus zeamais (Mots., 1855) (Coleoptera : Curculionidae). Arquivos do Instituto Biológico, São Paulo, v. 69, n. 2, p. 69-73, 2002.

HATTING, J. L.; WRAIGHT, S. P.; MILLER, R. M. Efficacy of Beauveria bassiana (Hyphomycetes) for control of russian wheat aphid (Homoptera: Aphididae) on resistant wheat under field conditions. Biocontrol Science and Technology, Canadá, v. 14, n. 5, p. 459-473, 2004.

HIDALGO, E.; MOORE, D.; LE PATOUREL, G. The effect of different formulations of Beauveria bassiana on Sitophilus zeamais in stored maize. Journal of Stored
Products Research, Oxford, v. 34, n. 2/3, p. 171-179, 1998.

LARA, F. M. Princípios de resistência de plantas a insetos. 2. ed. São Paulo: Ícone, 1991. 336 p.

LORINI, I. Pragas de grãos de cereais armazenados. Passo Fundo: Embrapa Trigo, Ministério da Agricultura, Pecuária e Abastecimento. 1999, 60 p.

. Produto natural à base de terra de diatomáceas para controle das pragas de grãos armazenados. Passo Fundo: Embrapa Trigo, Ministério da Agricultura, Pecuária e Abastecimento. 2002, 8 p.

MARSARO JÚNIOR, A. L.; LAZZARI, S. M. N.; FIGUEIRA, E. L. Z.; HIROOKA, E. Y. Inibidores de amilase em híbridos de milho como fator de resistência a Sitophilus zeamais (Coleoptera: Curculionidae). Neotropical Entomology, Piracicaba, v. 34, n. 3, p. 443450, maio/jun. 2005b.

MARSARO JÚNIOR, A. L.; LAZZARI, S. M. N.; KADOZAWA, P.; HIROOKA, E. Y.; GERAGE, A. C. Avaliação da resistência de híbridos de milho ao taque de Sitophilus zeamais Motschulsky (Coleoptera: Curculionidae) no grão armazenado. Semina: Ciências Agrárias, Londrina, v. 26, n. 2, p. 165-170, abr./jun. 2005a.

MATIOLI, J. C. Estimativas dos danos provocados em grãos de milho pelo ataque de Sitophilus oryzae (L., 1763) (Coleoptera, Curculionidae). Revista Brasileira de Armazenamento, Viçosa, v. 6, n. 1, p. 43-53, 1981.

MIRANDA; M. M. M.; ARAÚJO, J. M.; PICANÇO, M.; FALEIRO, F. G.; MACHADO, A. T. Detecção de não-preferência à Sitophilus zeamais Mots. em espigas e grãos de 49 populações de milho. Revista Brasileira de Armazenamento, Viçosa, v. 20, n. 1/2, p. 21-25, 1995.

MOINO JUNIOR, A.; ALVES, S. B. Efeito de Beauveria bassiana sobre o desenvolvimento de Sitophilus zeamais. Manejo Integrado de Plagas, Costa Rica, v. 50, p. 51-54, 1998.

PACHECO, I. A.; PAULA, D. C. Insetos de grãos armazenados: identificação e biologia. Campinas: Fundação Cargill, 1995, 228 p.

PADÍN, S.; DAL BELLO, G.; FABRIZIO, M. Grain loss caused by Tribolium castaneum, Sitophilus oryzae and Acanthoscelides obtectus in stored durum wheat and beans treated with Beauveria bassiana. Journal of Stored Products Research, Oxford, v. 38, n. 1, p. 69-74, 2002.

PARRA, J. R. P. Consumo e utilização de alimentos por insetos. In: PANIZZI, A. R.; PARRA, J. R. P. (Ed.). Ecologia nutricional de insetos e suas implicações no manejo de pragas. São Paulo: Manole, 1991. p. 9-66. 
POTRICH, M.; ALVES, L. F. A.; MERTZ, N. R.; SILVA, E. R. L. Avaliação de Beauveria bassiana (Bals.) vuill. e Metarhizium anisopliae (metsch.) sorok para controle de Sitophilus zeamais (Coleoptera: Curculionidae). Piracicaba: Bioassay, 2006. v. 1.

RAMALHO, F. S.; ROSSETO, C. J.; NAGAI, V. Comportamento de germoplasmas de milho sob a forma de palha e grãos debulhados em relação a Sitophilus zeamais motschulsky, 1855. Ciência e Cultura, São Paulo, v. 29, n. 5, p. 584-590, 1977.

RICE, W. C.; COGBURN, R. R. Activity of the entomopathogenic fungus Beauveria bassiana (Deuteromycotina: Hyphomycetes) against three coleopteran pests of stored grain. Journal of Economic Entomology, U.S.A., v. 92, n. 3, p. 691-694, 1999.

SANTOS, J. P. Recomendação para o controle de pragas de grãos e de sementes armazenadas. In: BÜLL, L. T.; CANTARELLA, H. (Ed.). Cultura do milho: fatores que afetam a produtividade. Piracicaba: Potafos, 1993. p. 197-233.

SANTOS, J. P.; FOSTER, J. E. Identificação de grãos de milho resistentes ao gorgulho. Pesquisa Agropecuária Brasileira, Brasília, v. 16, n. 1, p. 39-43, 1981a.

Preferência e reprodutividade do gorgulho do milho como fator de resistência em algumas populações e linhagens de milho. Pesquisa Agropecuária Brasileira, Brasília, v. 16, n. 6, p. 769-775, 1981 b.

THRONE, J. E.; EUBANKS, M. W. Resistence of tripsacorn to Sitophilus zeamais and Oryzaephilus surinamensis. Journal of Stored Products Research, Oxford, v. 38, p. 239-245, 2002.
TIPPING, P. W.; MIKOLAJCZAK, K. L; RODRIGUEZ, J. G.; PONELEIT, C. G.; LEGG, D. E. Effects of whole corn kernels and extracts on behavior of maize weevil (Coleoptera: Curculionidae). Journal of Economic Entomology, U.S.A., v. 80, n. 5, p. 1010-1013, 1987.

TIPPING, P. W.; RODRIGUEZ, J. G.; PONELEIT, C. G.; LEGG, D. E. Feeding activity of the maize weevil (Coleoptera: Curculionidae) on two dent corn lines and some of their mutants. Journal of Economic Entomology, Lanham, v. 81, n. 3, p. 830-833, 1988.

TOSCANO, L. C.; BOIÇA JUNIOR, A. L.; LARA, F. M.; WAQUIL, J. M. Resistência e mecanismos envolvidos em genótipos de milho em relação ao ataque do gorgulho, Sitophilus zeamais mots. (Coleoptera: Curculionidae). An. Soc. Entomol., Piracicaba, v. 28, n. 1, p. 141-147,1999.

VENDRAMIM, J. D. O controle biológico e a resistência de plantas. In: PARRA, J. R. P.; BOTELHO, P. S. M.; CORRÊA-FERREIRA, B. S.; BENTO, J. M. S. (Ed.). Controle biológico no Brasil: parasitóides e predadores. São Paulo: Manole, p. 511-528, 2002. cap. 30.

VOWOTOR, K.A.; BOSQUE-PÉREZ, N.A.;AYERTEY, J. N. Effect of maize variety and storage formo $n$ the development of the maize weevil, Sitophilus zeamais Motschulsky. Journal of Stored Products Research, Oxford, v. 31, n. 1, p. 29-36, 1995.

WAKEFIELD, M. E.; BRYNING, G. P.; CHAM,BERS, J. Progress towards a lure to attract three stored product weevils, Sitophilus zeamais Motschulsky, S. Oryzae (L.) and S. granarius (L.) (Coleoptera: Curculionidae). Journal of Stored Products Research, Oxford, v. 41, n. 2, p. 145-161, 2005. 